\title{
Fatigue of Fillet-welded Joint Assessment by the FEA Simulation of Damage Accumulation
}

\author{
Prof., Dr.Sci.Tech. R. V. Guchinsky, \\ IPME RAS; \\ Prof., Dr.Sci.Tech. S. V. Petinov*, \\ Saint-Petersburg State Polytechnical University
}

Key words: Fillet-welded joints; Fatigue of welded joints; FEA-based simulation of fatigue; Strain-life criterion for fatigue; Fatigue damage accumulation technique.

\section{Introduction}

Fillet-welded joints are frequent in steel structures applied in civil engineering, in ship and marine structures. Through recent decades, a design principle of welded structures, known as «friendly for manufacturing» assumed application of fillet-welded joints without machining the edges needed to provide complete filling of the joint, has been manifested.

Of special interest are the non-continuous part-penetration joints where the load flow passes via the weld material. A typical example is the welded joints of brackets in connection of outer shell stiffeners and transverse components of welded bridge and ship hull structures. The load flow due to axial deformation and bending of stiffeners is concentrated in the weld material at the bracket ending causing local stress elevation capable of initiating fatigue crack, Fig.1.

Another example is the "friendly for manufacturing" cruciform part-penetration load-carrying welded joints when machining of plate edges is not applied. Depending on the relative width of cavity (compared to plate thickness) and shape of weld bead fatigue failure in these joints may initiate at the weld toe or, alternatively, from the weld root, the cavity tip.

In uniformly loaded continuous fillet-welded joints the first problem, i.e. initiation of fatigue process at the weld toe, can be solved by following the International Institute of Welding (IIW) instructions, e.g. [6, 11], and the rules of International Association of Classification Societies (IACS), e.g. [7], for fatigue design of hull structures.

In case the crack is expected at the weld root fatigue strength can be assessed by applying the Fracture mechanics technique $[2,3,12$, etc. $]$.

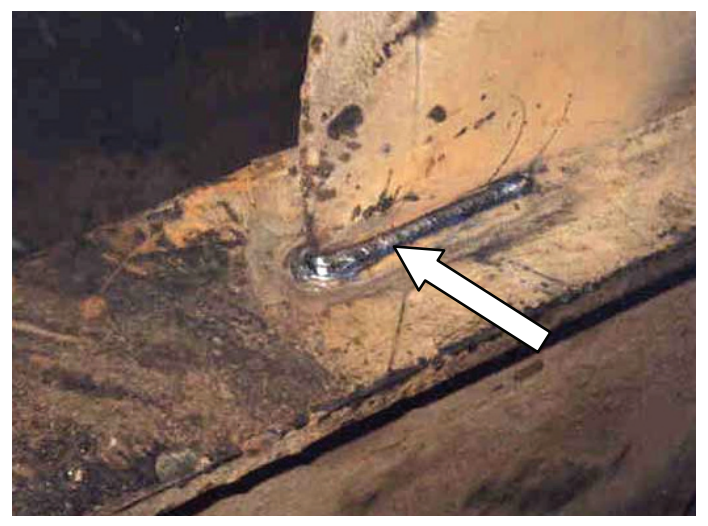

Fig. 1. Fatigue crack (re-welded) at the bracket ending on the flange of longitudinal stiffener. A tanker ship bottom structure. Courtesy of Lloyd's Register

Since the continuous uniformly loaded joints are considered in above references, the stress analysis can be reduced to the generalized plane stress problem. The crack path is approximately predicted by the FEA as the maximum principal stress planes passing through the weld throat. Respectively, the strength intensity factor (SIF) values along the crack path should be calculated. Further, the crack extensions are found by integrating the ParisErdogan equation, e.g. [3]. It should be immediately noted that the crack (SIF) analysis in this case is limited by the properties of stress field at the crack tip: the stress singularity vanishes as the crack traverses approximately 0.7 of the weld throat; apart from that increasing stress in the ligament actuates material plasticity, again, limiting applicability of the Linear fracture mechanics and the prospects of analysis.

Fatigue analysis is seen essentially more complicated when the crack initiation is expected at the weld root of the non-continuous and non-uniformly loaded joints. In such cases, planning fatigue and FE analysis of the joint, one has to foresee the crack initiation location and the three-dimensional crack progress until it would reach the outer surface of the weld bead. The mesh should be re-arranged following the crack front evolution and extensions. Again, the stress field singularity range may be limited and material plasticity would prevent the feasibility of analysis well before the crack might have approached the outer surface of the weld.

An attempt to approximate fatigue properties of non-continuous part-penetration fillet welded joint was made in [14] exemplified by the bending loaded cantilever plate, Fig.2. The intact weld bead stress field was used to approximately estimate the crack trace and the stress intensities, mostly at the weld ending. The results of analysis were in reasonable agreement with the experimentally obtained fatigue lives [8]. However, the agreement was found 
at relatively low stresses in the joint. At high stresses in the weld material the Linear fracture mechanics format was not applicable because of development of plasticity at the weld root. All in all, since the crack extensions were modeled rather conditionally, the approach developed could not be regarded a general technique of fatigue strength evaluation.

Recently [9] it was shown that crack initiation and growth in case of elastic-plastic deformation of material might be simulated aided by the FEA using the technique of «damage accumulation», even in polycrystalline silicon components. The idea of the approach is not a new one: it was suggested, e.g., in [1], [2], [5] and in earlier publications. However, modeling of the fatigue process in [9] as in other publications as well, was applied to the plane stress conditions, crack analysis in thin plane elements. In the present analysis the three-dimensional crack progress caused by exhausting of cyclic plasticity is simulated by applying the elements of the above approach. The results of simulation are in good agreement with the experimental data [8] obtained at large load excursions causing cyclic plasticity of weld material.

\section{Procedure of analysis}

According the present version of the approach, the volume of detail analyzed is modeled by the mesh, the finite elements in which are assumed "material elements», deemed representative of clusters of grains with approximately close slip resistance. This principle allows for statistical modeling of properties of slip resistance in «material elements» providing by this assessment of scatter in fatigue lives [9, 15]. Progressing damage of «material elements» is estimated by the linear damage summation (Palmgren-Miner) rule; the stress field and the damage evolution is accounted in the course of crack extensions. The "failed» elements where the damage reaches the "critical unity" are defined further by the infinitesimal stiffness, thus allowing for the crack initiation and extensions simulation.

In present analysis the elements of this technique are applied for the numerical simulation of fatigue process in non-continuous non-uniformly loaded fillet-welded joint, where the crack is assumed initiated in cavity, at the weld root. The damage accumulation is based on considering elastic-plastic behavior of material; the crack shape and extensions are simulated until almost complete failure of the joint, when the crack approaches the outer surface of the weld and propagates along the weld in the throat plane.
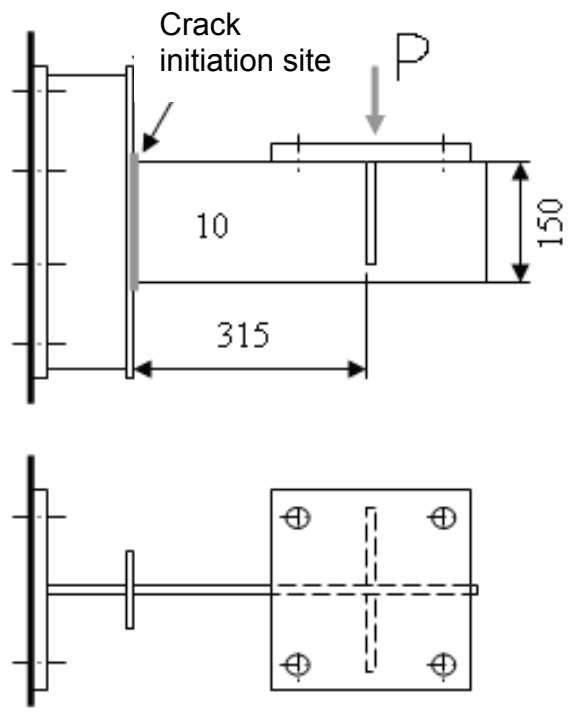

\section{Fig. 2. Specimens tested and results reported in [9]}

Fatigue resistance of material, a low-carbon structural steel electrode material, is characterized by the Strain-life Manson's criterion [10, 13]:

$$
\Delta \varepsilon=\Delta \varepsilon_{p}+\Delta \varepsilon_{e}=C N^{-\alpha}+B N^{-\beta}
$$

parameters of which, experimentally obtained, are: $C=0.480, B=0.011, \alpha=0.653, \beta=0.140$ [13]; $\sigma_{y}=290, M P a, \sigma_{u}=450, M P a, \Delta \varepsilon$ is the total cyclic strain range, $\Delta \varepsilon_{e}, \Delta \varepsilon_{p}$ are the elastic and plastic strain range components, respectively; $N$ is the number of cycles prior fatigue failure of material, defined by the preestablished decrease of the specimen stiffness. During fatigue tests of specimens the cyclic curves were recorded and generalized diagrams obtained [13].

As a reference, the specimen characteristics and loading mode given in [8], Fig.2, were used to design the FE model of the joint. In designing the FE model of the joint the attention was focused solely on the crack initiation at the slit tip circumference and propagation towards the outer surface of the weld bead. It was assumed that crack propagation surface insignificantly deviated from the weld throat plane.

The fracture modes in [8] were indicated only schematically; therefore the fractographic observations revealed in testing of similar fillet-welded joints where fatigue cracks propagated from the weld root [4] were used to support the above assumption, Fig. 3.

Respectively, the mesh was designed reasonably fine in the expected growth plane to provide the necessary cyclic stress and strain resolution (10 elements through the weld thickness in the throat plane); otherwise, it was coarsened, as shown in Fig.4, to reduce the processing time. 


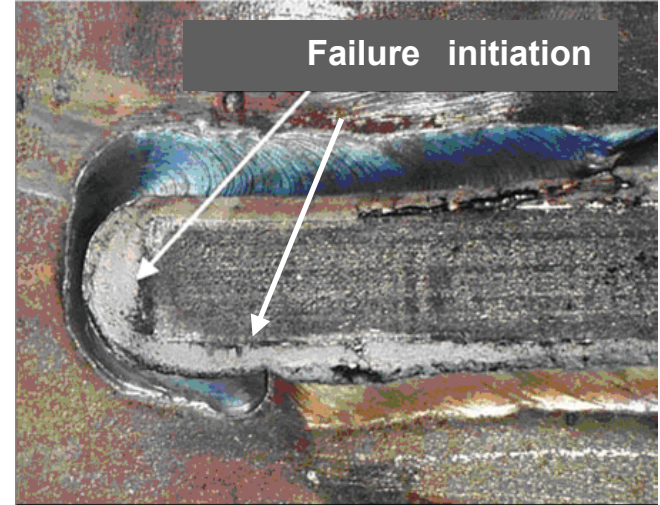

Fig. 3. Fracture of weld material initiated at the front and lateral edge of cavity [4]

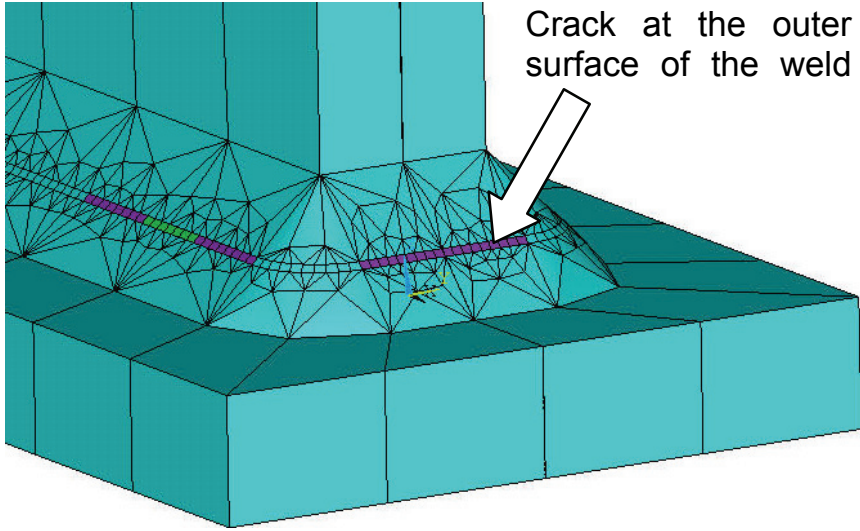

Fig. 4. FE model of the weld ending where crack initiation and growth is anticipated from the cavity caused by the lack of penetration of weld material

In the first load application, the static tensile diagram characterized the elastic-plastic behavior of elements of the model. In unloading, the behavior of elements, which exhibited plasticity in the initial phase, was further described by generalized cyclic curve. On assumption of cyclic stability of material (observed in experimental studies), calculated strain range was used to obtain the initial fraction of damage in affected "material elements».

The number of load cycles corresponding to estimated strain range is found from (1) by using maximum strain range in elements located, in the first step, at the circumference of the slit tip. This number is attributed to «failure» of these (or the only, if appropriate) elements. So far, if this number is $N_{o}$, then damage accumulated at this step in every of remaining affected elements is:

$$
d_{\text {initial }}=N_{0} / N_{i} .
$$

So that $n_{i}=N_{0}$ is the initial fragment of the "fatigue process», $N_{i}$ is the number of load cycles to failure in every of the strain range conditions, in every of «material elements» where plasticity occurred in the initial and sequential loadings, which develop due to "failure" of consequential elements. The "failure" is controlled by condition:

$$
d=d_{\text {initial }}+\sum_{i}\left(n_{i} / N_{i}\right)=1 .
$$

Here $n_{i}=n_{i}\left(\Delta \varepsilon_{i}\right)$ is the number of load cycles corresponding the strain range $\Delta \varepsilon_{j}$, which completes the damage accumulation in a particular FE («material element»), $d$, at every of the «crack extensions».

\section{Results of the fatigue process simulation}

The briefly displayed procedure allowed analyzing the crack "initiation" at the cavity circumference and its extensions until almost complete fracture of the joint in the weld throat surface. Fig. 5 shows the results of FE simulation of the crack initiated in several locations of the slit circumference and its growth towards the outer surface of the weld. As seen, the crack initiation is predicted not only at the weld ending inner boundary; also, simultaneous crack start is expected at a short distance from the weld ending, at the lateral tips of the cavity.

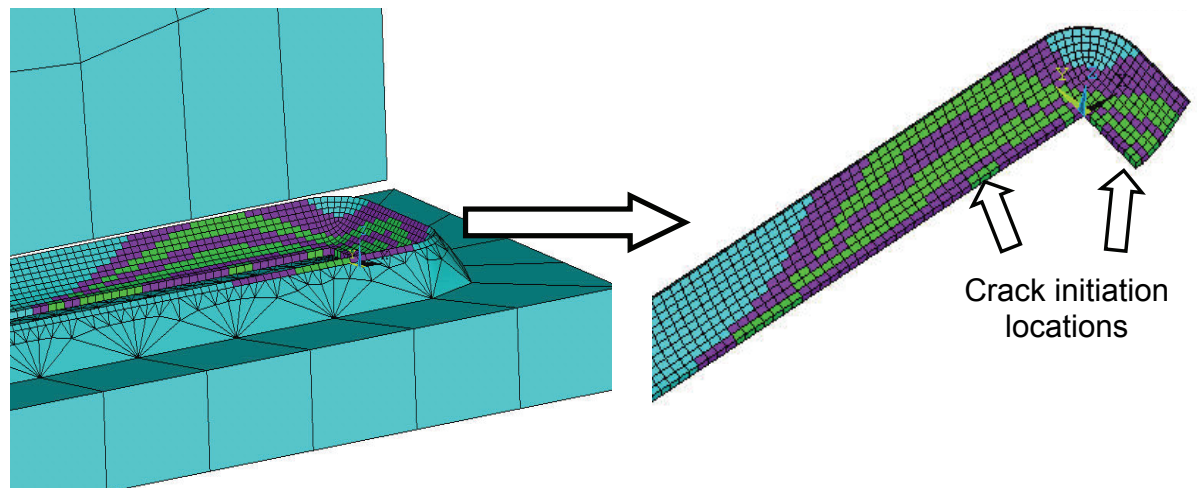

Fig. 5. Sequence of «failure» of elements and of the respective «crack extensions» initiated at the slit circumference

Guchinsky R. V., Petinov S. V. Fatigue of Fillet-welded Joint Assessment by the FEA Simulation of Damage Accumulation 
This corresponds to the findings of experimental investigation [4], Fig.3, and of the previous numerical analysis of the same joint, although the latter limited by the uncracked weld material conditions and assessed the axial tensile loading of the attachment [14], as seen in Fig.6.

The crack shape evolution shown in Fig.5, corresponds to 32, 57, 85, 94, 98 and $99 \%$ of the total fatigue life of the joint when the applied load excursions were equal to $\Delta P=48.33, \mathrm{kN}$. Similar were the general crack shape characteristics, although the crack extension steps were dependent on the load range, as occurred fatigue lives under different loading conditions as well.

The results of analysis of fatigue properties of the fillet-welded joint when the crack assumed initiated at the cavity due to incomplete penetration, altogether with the experimental findings are presented in Table 1 and in Fig.7.

It is seen, the results of fatigue process modeling by the damage accumulation in "material elements" procedure fit reasonably well the experimental data.

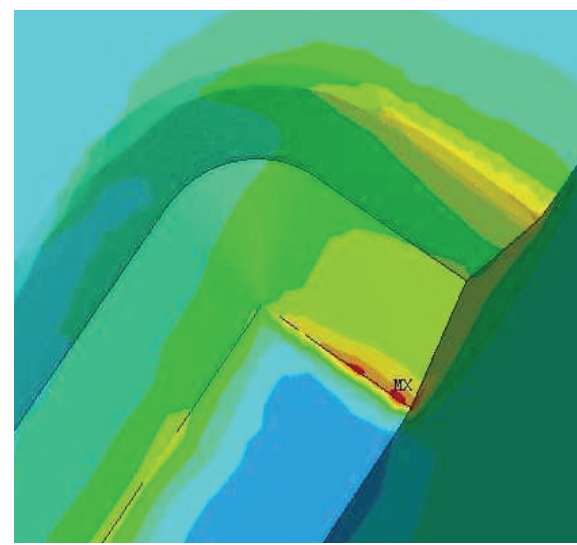

Fig. 6. Maximum principal elastic stress field in the weld throat plane; tensile loading of the joint [14]

Table 1. Fatigue life of the joint: test data [8] and results of numerical simulation

\begin{tabular}{|l|l|l|l|}
\hline $\begin{array}{c}\text { Reference stress } \\
\text { at the weld toe } \\
\mathbf{S}, \mathbf{M P a}\end{array}$ & \multicolumn{1}{|c|}{$\begin{array}{c}\text { Load excursion, } \\
\mathbf{P}, \mathbf{k N}\end{array}$} & \multicolumn{1}{c|}{$\begin{array}{c}\text { Fatigue life, } \mathbf{x ~ 1 0 ^ { 6 } ,} \\
\text { cycles, } \\
\text { experiment [9] }\end{array}$} & $\begin{array}{c}\text { Fatigue life, } \mathbf{x} \mathbf{1 0}^{\mathbf{6}}, \\
\text { cycles, simulated, } \\
\text { present analysis }\end{array}$ \\
\hline 188.05 & 22,748 & 3.075 & 5.940 \\
\hline 282.14 & 34,13 & 1.429 & 0.880 \\
\hline 305.62 & 36,97 & 0.819 & 0.604 \\
\hline 329.1 & 39,81 & $0.379-0.419$ & 0.415 \\
\hline 352.58 & 42,65 & 0.278 & 0.290 \\
\hline 399.54 & 48,33 & 0.084 & 0.155 \\
\hline
\end{tabular}

Discussing the comparison, it should be noted that repeating of testing of a series of specimens at the same load conditions would result in a scatter of test data. The sources of scatter may be attributed to the difference of the volume and the shape of weld material, especially at the weld ending, to the difference of particular size and shape of cavity in every of tested specimens. Those were uncertain; for the purposes of a more detailed analysis the geometry of the weld and slit should be assessed, e.g., by the means of ultrasonic scanning.

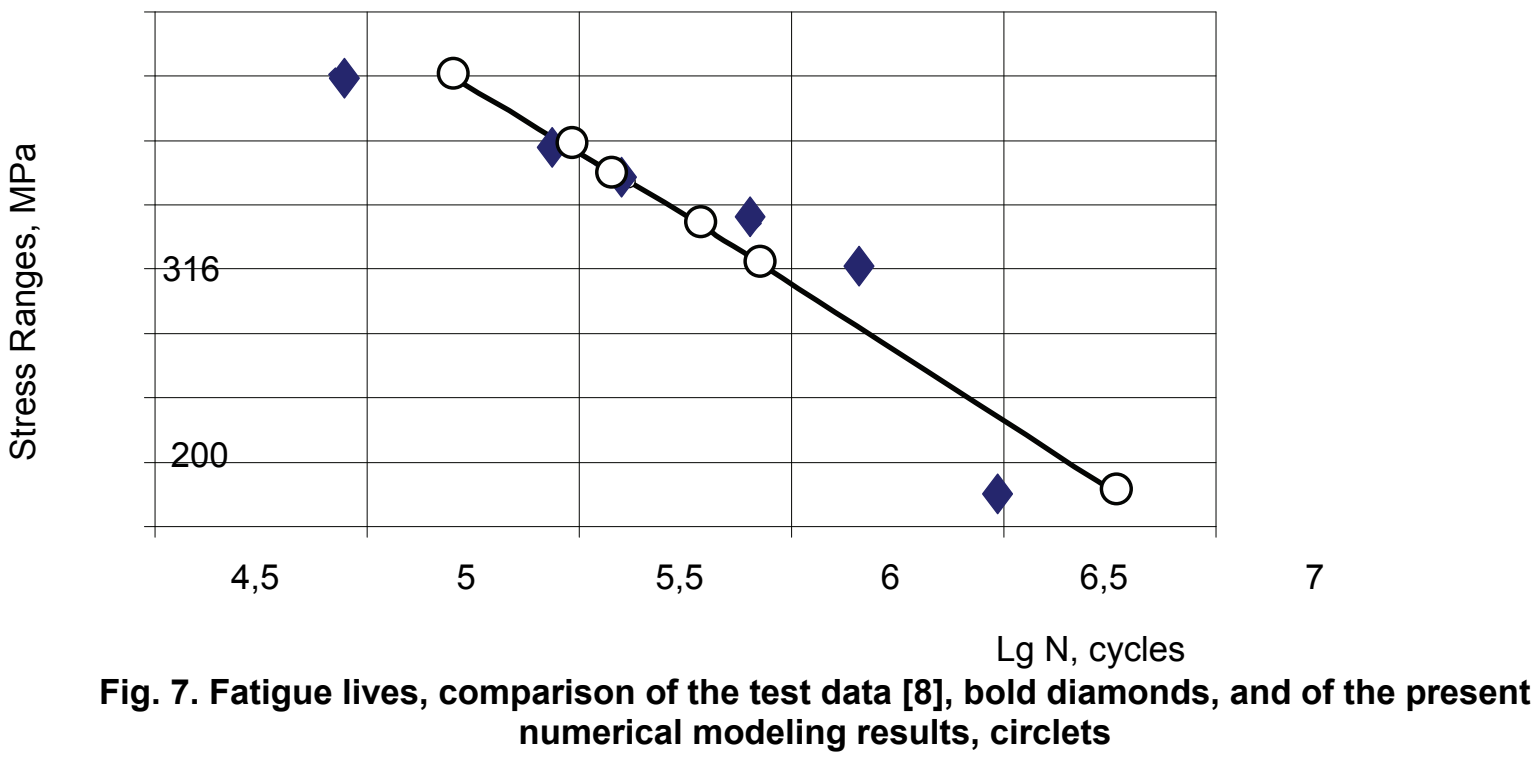

Guchinsky R. V., Petinov S. V. Fatigue of Fillet-welded Joint Assessment by the FEA Simulation of Damage Accumulation 
In addition, the present analysis did not consider residual welding stress and its influence on the fatigue process. However, it may be a factor of secondary importance in modeling fatigue of incomplete penetration welding joints: it was shown [16] that the most influential component of welding stress, normal to the expected crack propagation plane, is insignificant at the cavity tip, increasing towards the outer surface of the weld bead. Material cyclic plasticity induced at the crack front and in ligament would result further in the residual stress re-distribution and relaxation, so that total effect of welding stress may be neglected.

\section{Acknowledgements}

This work was carried out within the frames of the Program of fundamental research sponsored by the Division of Energy, Mechanical Engineering, Mechanics and Control of Processes of Russian Academy of Science.

\section{References}

1. Boytsov G. V. Обобщенный подход к расчету зарождения и развития трещин усталости в плоских элементах судовых конструкций [A Generalized Analysis of Initiation and Propagation Stages of Fatigue Cracks in Plate Elements of Ship Structures]. Proceedings, Gorky Polytechnic. 1990. pp.5-11.

2. Ellyin F., Fakinlede C. O. Probabilistic Simulation of Fatigue Crack Growth by Damage Accumulation. Engineering Fracture Mechanics. 1985. Vol. 22, No. 4. pp. 697-71

3. Frank K. H., Fisher J. W. Fatigue Strength of Fillet Welded Cruciform Joints. Journal of the Structural Division, ASCE. 1979. Vol.105, No.ST9. pp.1727-1741

4. Fricke W., Doerk O., Gruenitz L. Fatigue Strength Investigation and Assessment of Fillet-Welds around Stiffener and Bracket Toes. Proc. of Special FPSO Conference of OMAE. 2004. Houston, TX.

5. Glinka G. A Cumulative Model of Fatigue Crack Growth. International Journal of Fatigue. 1982. April. pp.59-67

6. Hobbacher A. Recommendations for Fatigue Design of Welded Joints and Components. 2007. IIW document XIII2151r1-07 / XV-1254r1-07.

7. IACS Common Structural Rules for Double Hull Oil Tankers. 2006

8. Kim W. S., Kim D. H., Lee S. G., Lee Y. K. Fatigue Strength of Load-Carrying Box Fillet Weldment in Ship Structure. Proceedings, $8^{\text {th }}$ International Symposium PRADS-2001. 2001. Vol. 2, pp.1161-1167, Shanghai. Elsevier Science Ltd.

9. Korolev I. K., Petinov S. V., Freidin A. B. FEM Simulation of fatigue damage in a polycrystalline silicon structure. Proc., VI Intern. Conference on Reliability of Materials and Structures «RELMAS-2008». Saint-Petersburg, SPb Polytechnic University, 2008.

10. Makhutov N. A. Деформационные критерии усталости и прочность компонентов конструкций [Strain-Life Criteria for Fatigue Failure and Strength Analysis of Structural Components]. Mashinostroenie, Pubs, Moscow. 1981.

11. Niemi E. Structural Stress Approach to Fatigue Analysis of Welded Components. Designer's Guide. 2000. IIW Doc. XIIIWG3-06-99

12. Petinov S. V. Crack Propagation Period of Fatigue and Prediction of Structure Fatigue Life. Report SK/R-36, Division of Ship Structures, NTH, Trondheim. 1976.

13. Petinov S. V. Fatigue Analysis of Ship Structures. Backbone Publishing Co., P.O. Box 562, Fair Lawn, NJ 07410.2003.

14. Petinov S. V., Kim W. S., Paik Y. M. Assessment of Fatigue Strength of Weld Root in Ship Structure: An Approximate Procedure. Ship and Offshore Structures Journal. Woodhead Publishing, V.1, No.1, 2006, pp.55-60.

15. Petinov S. V., Letova T. I., Yermolaeva N. S. FEM Modeling of the Aluminium Alloy Microplasticity. In: Advanced Light Alloys and Composites. NATO ASI Series. 1998 / Ed. by R. Ciach. Kluwer Academic Publishers, Dordrecht, pp. 427-433.

16. Karzov G. P., Margolin B. Z., Shvetsova V. А. Физическое и механическое моделирование процессов разрушения [Physical and Mechanical Modeling of the Failure Processes]. Saint-Petersburg : Polytechnic Publ., 1993.

* Sergei V. Petinov, Saint-Petersburg, Russia

Tel: +7 (812) 552-6303; email: sergei.petinov@gmail.com 
doi: 10.5862/MCE.22.5

\title{
Fatigue of Fillet-welded Joint Assessment by the FEA Simulation of Damage Accumulation
}

\author{
R. V. Guchinsky, \\ IPME RAS, Saint-Petersburg, Russia \\ S. V. Petinov, \\ Saint-Petersburg State Polytechnical University, Saint-Petersburg, Russia \\ +7 (812) 552-6303; e-mail: sergei.petinov@gmail.com
}

\section{Key words}

Fillet-welded joints; fatigue of welded joints; FEA-based simulation of fatigue; strain-life criterion for fatigue; fatigue damage accumulation technique

\begin{abstract}
Fatigue strength evaluation of non-continuous incomplete penetration fillet-welded joints transferring stress flow by the S-N criteria incorporating the «Hot-spot stress» or «Notch-stress» approaches is dubious since the characteristic stress at the crack initiation location is not established by the rules for fatigue design. Application of the linear fracture mechanics (LMF) technique meets a problem of numerical modeling the crack three-dimensional shape and front extension, which becomes insoluble when the crack approaches the outer surface of weld bead and propagates along the seam. Apart from that, considering material plasticity beyond the initial phase of crack extensions from the cavity is off the frames of the principles of the LMF.

An approach based on the FEA simulation of fatigue damage accumulation is suggested and applied to evaluate the crack initiation at the cavity and propagation in the non-continuous fillet-welded joint. The crack initiation at the cavity, its three-dimensional shape formation and evolution are simulated taking into account the elastic-plastic cyclic deformation of weld material until almost complete failure of the joint. The results of analysis are in good agreement with published experimental data.
\end{abstract}

\section{References}

1. Boytsov G. V. Proceedings, Gorky Polytechnic. 1990. pp.5-11. (rus)

2. Ellyin F., Fakinlede C. O. Probabilistic Simulation of Fatigue Crack Growth by Damage Accumulation. Engineering Fracture Mechanics. 1985. Vol. 22, No. 4. pp. 697-71

3. Frank K. H., Fisher J. W. Fatigue Strength of Fillet Welded Cruciform Joints. Journal of the Structural Division, ASCE. 1979. Vol.105, No.ST9. pp.1727-1741

4. Fricke W., Doerk O., Gruenitz L. Fatigue Strength Investigation and Assessment of Fillet-Welds around Stiffener and Bracket Toes. Proc. of Special FPSO Conference of OMAE. 2004. Houston, TX.

5. Glinka G. A. Cumulative Model of Fatigue Crack Growth. International Journal of Fatigue. 1982. April. pp.59-67

6. Hobbacher A. Recommendations for Fatigue Design of Welded Joints and Components. 2007. IIW document XIII2151r1-07 / XV-1254r1-07.

7. IACS Common Structural Rules for Double Hull Oil Tankers. 2006

8. Kim W. S., Kim D. H., Lee S. G., Lee Y. K. Fatigue Strength of Load-Carrying Box Fillet Weldment in Ship Structure. Proceedings, $8^{\text {th }}$ International Symposium PRADS-2001. 2001. Vol. 2, pp.1161-1167, Shanghai. Elsevier Science Ltd.

9. Korolev I. K., Petinov S. V., Freidin A. B. FEM Simulation of fatigue damage in a polycrystalline silicon structure. Proc., VI Intern. Conference on Reliability of Materials and Structures «RELMAS-2008». Saint-Petersburg, SPb Polytechnic University, 2008.

10. Makhutov N. A. Deformatsionnye kriterii ustalosti i prochnost komponentov konstruktsiy [Strain-Life Criteria for Fatigue Failure and Strength Analysis of Structural Components]. Mashinostroenie, Pubs, Moscow. 1981. (rus)

11. Niemi E. Structural Stress Approach to Fatigue Analysis of Welded Components. Designer's Guide. 2000. IIW Doc. XIIIWG3-06-99.

12. Petinov S. V. Crack Propagation Period of Fatigue and Prediction of Structure Fatigue Life. Report SK/R-36, Division of Ship Structures, NTH, Trondheim. 1976.

13. Petinov S. V. Fatigue Analysis of Ship Structures. Backbone Publishing Co., P.O. Box 562, Fair Lawn, NJ 07410. 2003. 
14. Petinov S. V., Kim W. S., Paik Y. M. Assessment of Fatigue Strength of Weld Root in Ship Structure: An Approximate Procedure. Ship and Offshore Structures Journal. Woodhead Publishing, V.1, No.1, 2006, pp.55-60.

15. Petinov S. V., Letova T. I., Yermolaeva N. S. FEM Modeling of the Aluminium Alloy Microplasticity. In: Advanced Light Alloys and Composites. NATO ASI Series. 1998 / Ed. by R. Ciach. Kluwer Academic Publishers, Dordrecht, pp. 427-433.

16. Karzov G. P., Margolin B. Z., Shvetsova V. A. Fizicheskoe i mekhanicheskoe modelirovanie protsessov razrusheniya [Physical and Mechanical Modeling of the Failure Processes]. Saint-Petersburg : Polytechnic Publ., 1993. (rus)

Full text of this article in English: pp. 5-9 